\title{
MITO E POLÍTICA NA TRAGÉDIA PERSAS DE ÉSQUILO
}

\author{
JAA TORRANO* \\ Faculdade de Filosofia, Letras e Ciências Humanas \\ Universidade de São Paulo
}

RESUMO: Representada em 427 a.C., e considerada hoje a mais antiga das tragédias que nos chegaram, a tragédia de Ésquilo intitulada "Persas" investiga o sentido de fatos da história política recente, servindose do imaginário e de noções próprias do pensamento mítico. Recentes eram a invasão da Ática pelos persas e a inesperada vitória dos gregos comandados por atenienses sobre as forças invasoras. Como se explicam essa derrota e vitória inesperada, sob a perspectiva do imaginário e das noções próprias do pensamento mítico? Que relação se estabelece, nessa tragédia, entre o pensamento mítico e a reflexão política? Mas, antes, o que é mito e o que política, no texto da tragédia e em seu contexto?

PALAVRAS CHAVE: Ésquilo; Os Persas; tragédia grega; pensamento mítico; política; Xerxes; hýbris.

O uso de recursos próprios ao pensamento mítico permitiu à tragédia de Ésquilo a elaboração da reflexão sobre os limites inerentes à distribuição do poder na pólis, antes que a teoria política filosófica fosse construída conceitualmente nos Diálogos de Platão.

Para observarmos esse uso de recursos próprios do pensamento mítico na elaboração da reflexão sobre os limites inerentes à distribuição do poder na pólis, reconsideremos um trecho da tragédia Agamêmnon de Ésquilo, e trechos de outra tragédia de Ésquilo Persas.

Na tragédia Persas, nos anapestos iniciais, o coro se apresenta como os "fiéis" (pistá, Pe. 2), anciãos escolhidos pelo próprio rei Xerxes para vigiarem a região, durante a ausência do rei e de seu exército, que partiram em expedição contra a Grécia. Já no primeiro verso, uma ambigüidade ominosa ressoa no particípio oikhoménon, "que partiram", ou ainda "que se foram", "os finados". Embora imedia- 
tamente rechaçada com o adjunto adverbial "à terra grega" (Hellád' eis aîan, Pe. 2), essa ambigüidade ressurge como um "maligno pressago ímpeto íntimo" (kakómantis... thymòs ésothen, Pe. 10-11), que pela falta de notícias invade os corações com as inquietantes e temerosas saudades dos que partiram de Susa, de Ecbátana e "da antiga torre císsia" (Pe. 16-17).

O catálogo dos chefes persas e a descrição de seu exército insistem tanto na opulência e riqueza quanto na magnitude do poder militar, e fecham-se com o retorno ao pranto e à dor das saudades (neòn d'/ ándra baúzei, Pe. 12-13; póthoi sténetai malerôi, Pe. 62).

O párodo lírico (Pe.65-139), dividido em seis pares de estrofes e antístrofes, abre-se com o anúncio da primeira extraordinária proeza desse exército: a ponte sobre o Helesponto, "lançada multicravejada via: jugo / ao redor do pescoço do mar" (Pe. 71-72).

O rei Xerxes e seu exército se descrevem como uma epifania de Ares, o Deus que se manifesta na carnificina. Ao rei se atribui o epíteto épico de Ares "impetuoso" (thoúrios, Pe. 74); assinala-se a sua origem em Zeus através de Perseu ("de áureo sêmen / nascido", Pe. 79-80), e assim lhe cabe o epíteto épico "varão igual a Deus" (isótheos phós, Pe. 80). Ele conduz o seu exército como ao "hábil arqueiro Ares" (toxódamnon Áre, Pe. 80), "a grande vaga de varões", "incombatível" e "irresistível" (Pe. 89-92).

Essa sobreposição de poderes humano e divino na figura do rei e de seu exército suscita no coro de conselheiros persas um temor inevitável: o temor de que essa opulência e grandeza tão extraordinária que se deixa confundir com a manifestação mesma de Deus revele-se afinal o "fraudulento logro de Deus" (Pe. 93).

A terceira estrofe e antístrofe do párodo (Pe. 93-101) apresentam a doutrina arcaica da "recusa dos Deuses" (Theôn phthónos), sem usar essas palavras, mas os termos equivalentes "fraudulento logro de Deus" (dolómetin d'apátan Theoû, Pe. 93). Essa doutrina, bem difundida no período arcaico e bem documentada em Heródoto, aparentemente teológica, tem um caráter eminentemente político. Muitos ilustres helenistas crêem erroneamente que Ésquilo a tivesse refutado nos versos 750-762 de Agamêmnon, onde em verdade a reitera e confirma, dando-lhe - a meu ver - límpida expressão:

"Prístino entre mortais velho provérbio diz: quando grande 
a opulência humana

procria e não morre sem filho.

De boa sorte, na família

a insaciável miséria floresce.

Mas sem os outros a sós penso:

que o ato ímpio

depois se multiplica

símil a sua origem,

pois nas casas com reta justiça

belo filho é o quinhão sempre."

(ÉSQUILO - Agamêmnon, 750-762)

Para que se compreenda corretamente o sentido reiterativo e confirmatório desses versos, é preciso que se atente para o sentido pejorativo da palavra mégan, "grande", no verso 751 de Agamêmnon, e para o sentido existencial da verificação empírica definitiva, no verso díkha d' állon monóphron ei(mí), "mas sem os outros a sós penso" (Ag. 757).

Desde Homero, nas expressões méga eipeîn, "falar com soberbia", e méga phroneîn, "ter pensamentos soberbos", a palavra mégas, "grande", tem o sentido pejorativo de "soberbo". Na tragédia, desenvolve-se a doutrina da hýbris, "soberbia", que vê a grandeza excessiva como uma usurpação de atribuições divinas indevida e imprópria para a condição humana. Na tragédia e no contexto político da democracia ateniense, essa doutrina ganha um caráter eminentemente político, ao mostrar as formas de agir compatíveis e não compatíveis com a vida e com a viabilidade política dos homens mortais no horizonte do governo do país.

No primeiro estásimo da tragédia Agamêmnon, o crime de Páris - rapto e ultraje às leis da hospitalidade - é explicado como áte, "erronia", decorrente da riqueza excessiva da cidadela de Príamo. Como a vitória do rei Agamêmnon sobre Príamo implica a superação deste por aquele, o coro de anciãos, em sua observação isenta e lúcida, pode por si mesmo prever as conseqüências de uma grandeza excessiva. É essa previsão, que faz por si mesmo o coro observador isento e lúcido, que confere às palavras com que o coro se refere a si mesmo no verso díkha d' állon monóphron ei (mí), "mas sem os outros a sós penso" (Ag. 757), o sentido existencial de uma verificação empírica tão definitiva que permite prever o porvir.

No párodo de Persas, a descrição da magnitude extraordinária do exército do rei provoca no coro de conselheiros do rei o temor de que tamanha grandeza se 
converta em áte, "erronia", por um "fraudulento logro de Deus". Note-se que áte é uma das figurações do divino, e que nessa expressão "logro de Deus", ainda que qualificado de "fraudulento", "Deus" é o sujeito e não o objeto do "logro". A noção mítica de "Deu(es)" se refere sempre ao fundamento e assim ao sujeito dos acontecimentos e das ações, mas isso não isenta absolutamente o mortal da responsabilidade por ter incorrido no "fraudulento logro de Deus", como deixa claro o desenvolvimento deste drama.

A doutrina da hýbris, tal como aparece disseminada nos coros trágicos, ensina que a grande prosperidade (ólbos), riqueza (ploûtos), boa sorte (agathâs týkhas) ou boa situação (êu prássein) induz os mortais nessa situação à soberbia (hýbris), e suscita a recusa dos Deuses (Theôn phthónos), quando os mortais prósperos e soberbos se tornam presa de erronia (áte), de modo agirem em detrimento de seus próprios interesses, ignorando-os, e arruinando-se (ólethros). Essa doutrina pressupõe que a grande riqueza ou felicidade é intrinsecamente má, iníqua e prejudicial a quem a desfruta. Por isso, a rememoração do quinhão divino que agraciou os persas com o arrojo e as vitórias militares e com a competência e o bom desempenho nas aventuras marítimas angustia e apavora o coro de conselheiros reais, e torna a suave dor e lânguidas saudades das esposas persas, solitárias desde a partida do grande exército, um pressentimento maligno no coração dos conselheiros (Pe. 103-139).

A rainha é anunciada pelo corifeu como "esposa de Deus de persas" e "também mãe de Deus / se o Nume antigo hoje não abandonou o exército." (Pe. 157158). Essa reiterada confusão entre o soberano e o Deus, mais do que um traço eloqüente do despotismo pérsico, soa blasfema à piedade grega, e assim indica uma soberbia contumaz, fadada certamente ao desfavor divino e à desgraça, que se anunciam ominosamente na cláusula condicional "se o Nume antigo hoje não abandonou o exército" (Pe. 158).

O que no párodo ainda é um pressentimento difuso, ainda que insistente, torna-se, na primeira cena do primeiro episódio, um claro sinal numinoso no sonho e no auspício que a rainha conta ao coro, pedindo-lhe um conselho. Desde a partida do exército, a rainha também convive com a ansiedade que lhe multiplica os sonhos, mas nenhum tão claro quanto esse, que ela conta:

O sonho (Pe. 181-200) - como a rainha mesma o diz - é em si mesmo claro, e a sua exposição pela rainha nos permite ver no próprio sonho uma interpretação do sentido e das conseqüências da proeza perpetrada pelo rei Xerxes e seu exército ao unir Ásia e Europa, lançando sobre Helesponto uma "multicravejada via" como "jugo / ao redor do pescoço do mar" (Pe. 70-73). 
Bastante claro, o sonho, entretanto, é acompanhado de um auspício que lhe consigna o valor inequívoco de uma revelação numinosa. Quando a rainha se prepara, após esse sonho, para fazer oferendas aos Numes protetores, vê uma águia refugiar-se junto ao altar de Febo, perseguida por um falcão, que em seguida a ataca sem encontrar resistência. O caráter premonitório do sonho e do auspício se verificará na violenta e bem sucedida recusa dos gregos ao jugo imposto por Xerxes, e na queda do rei e na dilaceração de suas vestes.

Diante desse auspício e do pavor que infunde, resta à rainha, como último recurso para reaver a tranqüilidade de ânimo, a proclamação do caráter despótico da soberania de seu filho, não sujeito à prestação de contas de seus atos à comunidade política (oukh apeúthynos pólei, Pe. 213), e além disso saber que conselhos para ela os anciãos conselheiros teriam. Outra marca despótica da realeza pérsica se mostra na extrema cautela com que os anciãos lhe respondem, aconselhando-a a fazer preces e súplicas aos Deuses e ao finado rei Dario.

Anunciado pelo corifeu como portador de um relato completo, verídico e claro, bom ou mau de ouvir (Pe. 246-248), o mensageiro faz o seu relato terrível de ouvir, com a notícia de súbita e completa perdição trazida pela derrota do exército persa. O mensageiro ressalta a sua autoridade de testemunha ocular ("presente e não por ouvir falas alheias, / persas, posso dizer que males se deram” Pe. 266-267), e converge com o coro no reconhecimento de que Salamina e Atenas são para os persas nomes funestos e lembranças odiosas e hediondas (Pe. 284-289).

Depois de novos catálogos de nomes persas (Pe. 290-349), que, completados com descrições de naufrágios e massacres, retomam em tom lutuoso os catálogos de tom saudoso do párodo, o mensageiro descreve a batalha de Salamina (Pe. 350-434). A rainha indaga "que princípio teve a batalha naval", se a principiaram os gregos ou seu filho "ufano de tantos navios" (Pe. 350-352). A longa resposta do mensageiro mostra a sobreposição em que coincidem "um ilatente ou mau Nume dalgures surgido" (Pe. 354) e "um grego vindo do exército ateniense" (Pe. 355), e ainda "a fraude do grego" (Pe. 361-362) e "a recusa dos Deuses" (Pe. 362). Como antes, no párodo, o poder e a grandeza do rei Xerxes e de seu exército se deixava confundir com a epifania do Deus Ares, agora essa fusão favorece os inimigos, pois é na astúcia e vitória dos inimigos que se manifesta a malícia e o poder dos Deuses.

A descrição do massacre na ilhota defronte de Salamina (Pe. 435-477) amplia e ressalta a ironia divina. "Os persas que estavam no máximo vigor, / os mais corajosos e os mais nobres, / os que sempre foram os mais leais ao rei" (Pe. 441-443), enviados por Xerxes à ilhota para que "se náufragos / inimigos tentassem fugir para 
a ilha / facilmente pudessem matar o exército grego, / e salvassem os amigos dos caminhos do mar" (Pe. 450-453), após a vitória naval dos gregos, foram todos massacrados à vista de Xerxes, "pois de seu posto via bem todo o exército, / num alto monte perto da planície do mar" (Pe. 466-467).

O comentário da rainha à notícia desse massacre aponta o "hediondo Nume" (stygnè Daîmon, Pe. 472) como o autor da "fraude do grego" (Pe. 361-362), ao acusá-lo de ter ludibriado os persas (hos ar'épseusas phrenôn / Pérsas, Pe. 472-473). No entanto, essa causalidade da autoria divina, aos olhos da rainha, não isenta o seu filho Xerxes de responsabilidade pelo infortúnio ("Crendo que cobrava reparação, meu filho / atraiu sobre si tão numerosos males" (Pe. 476-477).

Ao ser informada da fuga desordenada dos persas após a derrota, quando se multiplicam as perdas do exército persa, por fome, sede, fadigas e desastres, com o que se ressalta o desfavor divino. (Pe.478-531), a rainha reconhece a veracidade de sua "visão noturna, manifesta em sonho" (Pe. 518), e diz que fará as oferendas à Terra e aos mortos, recomendadas pelos anciãos, e pede-lhes que consolem e conduzem seu filho ao palácio, temerosa de que acabrunhado pela derrota ele se matasse. Não obstante esse pedido, o coro o receberá com dureza e sarcasmo.

No primeiro estásimo, o prelúdio anapéstico (Pe. 532-547) primeiro atribui a Zeus rei a causa da derrota persa e do luto sombrio que cobre as capitais do império, Susa e Ecbátana, e depois descreve a dor e o pranto das viúvas persas, enlutadas e saudosas. Na primeira estrofe (Pe. 548-557), uma tríplice anáfora (Pe. 550-552) põe Xerxes como sujeito da condução e destruição completa do exército persa, contrapondo-o a Dario, descrito como "incólume arqueiro rei", "condutor querido de Susa" (Pe. 555-557), o que implica um súbito esquecimento da desastrosa batalha de Salamina, antes aludida pelo corifeu (cf. Pe. 236 e 244). No entanto, na primeira antístrofe (Pe. 558-567), a tríplice anáfora correspondente substitui o nome de Xerxes pelo de "naves" (nâes, Pe. 560-562) como sujeito da condução e destruição da infantaria e da marinha; e os navios mesmos ("e os braços dos jônios", Pe. 563) parecem inculpados do desastre, e o rei parece então figurar como se, atingido, a "escapar por pouco" (tytthà d'ekphygeîn ánakt', Pe. 564).

A segunda estrofe (Pe. 568-576) evoca Salamina, descrevendo-a como os "pontais de Cicreu", lá onde mortos persas rodopiam, e contrapõe a essa evocação o pranto doloroso e prolongado entre os persas. Ampliando o tema dos mortos e do luto fúnebre, a segunda antístrofe (Pe. 577-583) evoca os cadáveres arrastados pelo mar e dilacerados pelos peixes, e as mortes pranteadas em casa pelos pais privados de filhos e aquinhoados com numinosas dores. 
O terceiro e último par de estrofe e antístrofe (Pe. 584-597) prevê as conseqüências políticas da derrota persa: rebeliões e insurreições, a desmoronarem o império, e conclui com outra evocação dos despojos persas, sepultados na lavoura sangrenta de Salamina.

No segundo episódio (Pe. 598-622), a rainha mesma assinala o contraste entre a sua primeira entrada, luxuosa e magnificente num carro real, e esta segunda, despojada de todo luxo e pedestre, a refletir a diferença entre o que era então tensa expectativa e o que agora se sabe que são fatos consumados. Prepara-se o rito invocatório dos Deuses ínferos, entre os quais se inclui o finado rei Dario, pai do infausto rei Xerxes; enumeram-se as oferendas: leite, mel, água, vinho, azeite e flores; e a rainha pede ao coro que entoe os hinos propiciatórios.

No segundo estásimo (Pe. 623-680), no prelúdio anapéstico (Pe. 623-632), o coro deixa à rainha a tarefa de fazer as libações funerárias e assume o ofício da invocação com os hinos. Primeiro se invocam os "santos Numes ctônios, / Terra e Hermes, e o rei dos ínferos" com o pedido de que enviem "dos ínferos a alma à luz" (Pe. 628-630). Aqui "alma" (psykhèn, Pe. 630) tem o sentido homérico de "espectro", condizente com a classificação do finado rei entre os "mortais" (thnetôn, Pe. 632), ainda que entre eles se distinga como o único que poderia dizer o termo dos presentes males, caso tenham remédio. Em seguida, na primeira estrofe, o coro se dirige ao "venturoso / rei igual a Nume", perguntando-se se ele o ouve nos ínferos (Pe. 633-638). Na segunda antístrofe, reiteram-se a invocação "à Terra e outros / condutores dos ctônios" e o pedido do envio do rei morto à luz, reclassificado agora como "Nume grandíloquo, / Deus dos persas nascido em Susa". Essa aparente flutuação da categoria emprestada ao morto não contradiz com a inclusão inicial do rei morto entre os mortais, mas antes condiz com a sabedoria e felicidade que se reconhecerá a seu reinado, em contraste com o presente infortúnio. É em nome dessa sabedoria e felicidade que se justifica a invocação, de modo que a sabedoria resgatada pela manifestação do rei morto possa amenizar as dores das calamidades atuais. Desse modo, de todo se esquece agora o desastre militar de Maratona, antes aludido e mencionado (cf. Pe. 236 e 244).

No terceiro episódio (Pe. 681-851), o espectro do finado rei Dario interpela o coro, reconhecendo os anciãos persas como "fiéis de fiéis, coetâneos de minha juventude" (Pe. 681), e perguntando-lhes "por que dor o país padece, / geme, golpeia e faz uma fenda no chão" (Pe. 682s.) O espectro reconhece as circunstâncias de invocação junto ao túmulo, cheias de prantos e de gemidos psicagógicos (psykhagogoîs... góois "gemidos condutores de alma", Pe. 687); reconhece a esposa 
junto ao túmulo, e as libações, acolhidas de bom grado; encarece a sua irrupção entre os vivos, tanto por atribui-la a seu poder junto aos Deuses subterrâneos, quanto pela relutância e brevidade com que esses Deuses lhe concedem estar com os vivos; sabe que essas presentes circunstâncias significam "novo grave mal", e indaga ao coro "qual é entre os persas o novo grave mal" (Pe. 693).

Antigo temor reverencial impede o coro de falar diante do antigo rei para dizerlhe as desditas dos seus (Pe. 694-702). O espectro do rei então interpela a rainha como "nobre mulher, anciã companheira do leito" (Pe. 704), instando-a a cessar prantos e gemidos e a dizer-lhe algo claro, e emite um juízo pessimista sobre a condição humana, aparentemente para reconfortá-la e animá-la a falar (Pe. 705-708).

Interpelada, a rainha saúda o espectro do rei como "o mais feliz dos mortais todos" (Pe. 709), pela "longeva vida vivida como Deus entre os persas" e por ter morrido "antes de ver o fundo dos males" (Pe. 710-712), e anuncia a presente dor: "perdeu-se o poder dos persas" (Pe. 714).

Numa breve stikhomythía (Pe. 715-738), a rainha resume os fatos anunciados pelo mensageiro, e o espectro do rei revalida e explicita a interpretação dos fatos dada pela rainha: Xerxes, dito por ambos - a rainha e o espectro - "impetuoso" por transferência e por deslocamento do epíteto do Deus Ares (Pe. 718), pôs um jugo no pescoço do Helesponto, assistido por um Nume. $\mathrm{O}$ espectro do rei exclama: "Phê̂! Veio grande Nume, de modo a não pensar bem!" (hoste mè phroneîn kalôs, Pe. 725). A rainha analisa e descreve os fatos: a destruição da marinha e da infantaria conduzidas por Xerxes deixa a Ásia viúva, mortos os varões, mas Xerxes enfim "chegou bem à ponte jugo das duas terras" (Pe. 736) e ainda "não há sedição"(Pe. 737).

O espectro do rei vê nos fatos o cumprimento de oráculos (kresmôn prâxis, Pe. 739), e reitera e revalida a interpretação, já dada pelo coro no primeiro estásimo (Pe. 532), que atribui a destruição do exército persa tanto a Zeus (Pe. 532-533), quanto a Xerxes, às barcas marinhas e aos braços dos jônios (Pe. 550-4, 558-63). O espectro do rei diz que Zeus incumbiu Xerxes de "cumprir ditas divinas" (teleutèn thespháton, Pe. 740), e explica como se deu essa incumbência: pela audácia juvenil ("quando por si se apressa, Deus ainda assiste”, Pe. 742; "com nova audácia”, néoi thrásei, Pe. 744). Essa audácia juvenil se configura na construção da ponte de navios a jungir o pescoço do Helesponto, e na imprudência de pensar que "sendo mortal superaria / Posídon e todos os Deuses” (Pe. 749-750). Esta doença da mente dominou Xerxes e a vasta riqueza custosa, que pertenceu ao finado rei, está indefesa à mercê da sanha alheia (Pe. 750-751). 
O espectro do rei afirma que nenhum dos reis asiáticos anteriores fez perecer tanta gente quanto Xerxes, e elenca os reis, para confirmar, e conclui que ninguém antes causou tanta dor quanto Xerxes, seu filho, por ser novo, pensar novidades, e não se lembrar das instruções paternas (Pe. 760-787).

Quando o espectro se mostra inteiramente informado das circunstâncias presentes, e da presente dor e de suas razões, o coro interroga o espectro do rei com a questão que nessas circunstâncias se impõe aos conselheiros persas: "Como depois ainda / estaríamos bem, o povo persa?" (Pe. 788-789). Tendo sido invocado como "conselheiro divino" (theoméstor, Pe. 654-655), que "bem conduziu o exército" (stratòn ê̂ podoúkhei, Pe. 656), o espectro do rei corresponde à expectativa de que a invocação o investiu, desaconselhando ataques à Grécia e a manutenção de um exército tão numeroso, que a terra mesma se tornasse aliada dos inimigos de modo a matar de fome os numerosos demais (Pe. 790-794).

Quando o coro aventa a hipótese de que boa seleção e boa munição pudessem servir de garantia a um novo ataque (Pe. 795), o espectro do rei retoma as “ditas divinas" ou, por outra, os “oráculos de Deuses" (thesphátoisin, Pe. 801), não mais para desvendar o sentido das circunstâncias presentes, mas para revelar o dos fatos futuros; e prevê que poucos teriam a salvação do regresso, dentre a selecta facção do exército que Xerxes, persuadido por vãs esperanças, abandona na Grécia continental. Tantos males e tantas mortes constituem a "paga de soberbia e de planos sem Deus" (Pe. 808), que se descrevem como "pilhar / imagens de Deuses... queimar templos" e fazer desaparecer "altares e estátuas de Numes, / arrancadas a esmo, reviradas dos pedestais” (Pe. 809-812). O espectro do rei não só mostra conhecer os "oráculos de Deuses", mas ainda os atos e fatos pelos quais esses "oráculos de Deuses" se cumpririam, pois prediz a "grande libação de sangue / no chão de Platéia, sob a dórica lança" (Pe. 816-817).

A doutrina, que orienta a interpretação dos atos de Xerxes e os fatos vividos por seu extraordinário exército, apresenta-se como a conclusão da narrativa em que se analisam esses atos e fatos: "que mortal não deve ter soberbo pensar. / A soberbia, ao florescer, colhe a espiga / da erronia, onde a safra será de lágrimas" (Pe. 810-812). Essa condenação da "soberbia" (hýbris, Pe. 811) se funda na noção de que "Zeus punitivo vigia os demasiado/ soberbos pensamentos, severo juiz” (Pe. 827-828). Assim se fecha o círculo: o rei, senhor do cetro ao qual se prestam contas (Pe. 764), se não presta contas ao país (Pe. 213), presta-as no entanto a "Zeus punitivo", "severo juiz" (Zeús toi kolastès... eúthynos barýs, Pe. 827-828). A soberba audácia é ofensiva aos Deuses (theoblaboûnt' hyperkómpoi thrásei, Pe. 831). 
O louvor do reinado do antigo rei contrasta com o luto e o pranto das circunstâncias presentes no reinado de Xerxes, e consolida a doutrina, comum ao coro, à rainha e ao espectro do rei, de condenação da soberbia no governo do país.

O êxodo (Pe. 909-1076) põe em cena Xerxes, como se prestando ao coro contas pelos seus atos, respondendo ao coro que lhe pede notícias dos nobres persas e aliados que Xerxes, ao levar à Grécia, conduziu à destruição. O coro assim mostra extensamente, nessa longa última cena, que o rei, por poderoso que seja, se se dispensa de prestar contas de seus atos ao povo, não pode dispensar-se de prestar contas a "Zeus rei" (Zeùs basileús, Pe. 532), dito ainda "Zeus punitivo" (Zeús toi kolastés, Pe. 827) e "severo juiz" (eúthynos barýs, Pe. 828), nem pode ocultar aos seus essa prestação de contas a tal juiz.

\section{Nota}

* Professor Titular de Língua e Literatura Grega do PPG Letras Clássicas e do Curso de Graduação em Letras da FFLCH/USP.

\section{REFERÊNCIAS Bibliográficas}

AESCHYLUS. Persae. Edidit Martin L. West. Stutgard, Tubner, 1991.

AESCHYLUS. Persae. Edited with introduction and notes by A. Sidgwick. Bristol Classical Press, 1982.

AESCHYLUS. Persians. Edited with an Introduction and Commentary by Edith Hall. Warminster, Aris and Phillips, 1997.

ESCHYLE. Les Perses. Edition, introduction et commentaries sous la direction de Jacqueline de Romilly. Paris, P.U.F., 1974.

ESCHYLE. Les Suppliantes. Les Perses. Les Sept contre Thèbes, Prométhée Enchainé. Texte établi et traduit par Paul Mazon. Paris, Les Belles Lettres, 1963.

ÉSQUILO. Orestéia I - Agamêmnon. Estudo e tradução de Jaa Torrano. São Paulo, Iluminuras, 2004. 
TORRANO, Jaa. On Aeschylus' Persians - Myth and politics in the tragedy.

ABSTRACT: Staged in 427 b. C., and known as the most ancient of all Tragedies which survive, the Aeschylus tragedy entitled "Persians" researches the meaning of facts from recent political history, by means of images and of notions taken from mythical thought. Those political facts are the Persian invasion of Attica and the unhoped-for victory of the Greeks lead by Athenians on the invaders. How are we to explain such failure and the unexpected victory, from the perspective of the images and the notions taken from mythical thought? How could we relate, in this tragedy, mythical thought and political theory? Above all, what is myth and what is politics in the tragedy's text and context?

KEY WORDS: Aeschylus; Persae; Greek tragedy; mythical thought; politics; Xerxes, hýbris. 